\title{
Resistências e concepções para a gestão e promoção de qualidade de vida e saúde no trabalho
}

Resistance, Lived Conceptions for managing and promoting Quality of Life and Health at Work

Resistencias y concepciones para a Gestión y promoción de calidade de vida y salud en el trabajo

Viviane Arno Di Palma ${ }^{1}$ Beatriz Quiroz Villardi ${ }^{2}$

\section{Resumo}

No contexto organizacional do mundo atual, percebem-se consequências negativas advindas das transformações aceleradas presentes na produção de bens e serviços, precarizando o trabalho. Para propiciar a Qualidade de Vida Trabalho- QVT e estimular bem-estar no ambiente laboral são elaborados ações pelas áreas de gestão de pessoas e de saúde ocupacional que nem sempre são bem-sucedidas. Esse insucesso parece estar vinculado ao fenômeno da resistência dos usuários a novos programas ou

\footnotetext{
${ }^{1}$ Fisioterapeuta, Mestre em Gestão e Estratégia pela UFRRJ, Especialista em Fisioterapia aplicada a traumato-ortopedia (Universidade Estácio de Sá), Graduada em Fisioterapia (Universidade Gama Filho). Coordenadora Geral da Coordenação de Atenção a Saúde e Segurança do Trabalhador- CASST da UFRRJ, Unidade do Sistema Integrado de Atenção Saúde Servidor Público FederalSIASS.

Email: vivianedipalma@gmail.com.

${ }^{2}$ Doutora em Administração de Empresas, com Estágio Pós Doutoral realizado sob o Edital Capes ColCiencias (Universidade Simón Bolívar, Colômbia); Mestre em Administração na Área de Concentração Planejamento e Organizações (Pontifícia Universidade Católica do Rio de Janeiro); Bacharel em Administração de Empresas Públicas e Privadas (Universidade Federal Rural de Rio de Janeiro). Professora Doutora Associado II no Departamento de Administração Pública da Universidade Federal Rural Do Rio de Janeiro no qual atua como Membro do Núcleo Docente Estruturante. Professora docente permanente do Mestrado em Gestão e Estratégia - MPGE da UFRRJ

Email: rbvillardi@hotmail.com.
}

serviços ofertados em uma instituição. Por ser recente a promoção de QVT no Serviço Público Federal, as ações condizentes a uma política de promoção e proteção à saúde do trabalhador significam uma inovação na instituição pesquisada. Visto que tal promoção a QVT constitui um novo tipo de serviço a ser ofertado, para efetivá-la cabe romper resistências ou barreiras surgidas, seja em variáveis situacionais ou individuais da organização. Para tanto, evidenciar concepções sobre QVT, decorrentes da vivência quotidiana dos servidores, e identificar as resistências por eles percebidas na adoção desses programas serve como ponto de partida para subsidiar a formulação de estratégias de rompimento dessas barreiras. Foram reveladas quatro concepções e quatro resistências que se recomenda considerar para uma efetiva implantação das ações de promoção da QVT.

Descritores: Resistências à inovação; Concepções Vividas; Qualidade de Vida e Saúde no Trabalho; servidor público, análise qualitativa interpretativa. 


\section{Abstract}

In the organizational context of the current world, negative consequences can be seen from the accelerated transformations present in the production of goods and services, making work precarious. In order to promote Quality of Work Life -QWL and stimulate well-being in the workplace, actions are elaborated by the areas of people management and occupational health that are not always successful. This failure seems to be linked to the phenomenon of users' resistance to new programs or services offered in an institution. As the promotion of QWL in the Federal Public Service is recent, the actions consistent with a policy of promotion and protection of workers' health mean an innovation in the researched institution. Since such promotion of QWL is a new type of service to be offered, to effect it, it is necessary to break resistances or barriers arising either in situational or individual variables of the organization. Therefore, highlighting conceptions about QWL arising from the daily experience of the servants and identifying the resistances perceived by them in the adoption of these programs, serves as a starting point to support the formulation of strategies to break these barriers. Four conceptions and four resistances that are recommended to be considered for an effective implementation of QWL promotion actions were revealed.
Keywords: Innovation Resistance; Lived Conceptions; Quality of work life; Public servant; Interpretive analysis.

\section{Resúmen}

En el contexto organizativo del mundo actual, se pueden ver consecuencias negativas de las aceleradas transformaciones presentes en la producción de bienes y servicios, haciendo que el trabajo se torne precario. Con el fin de promover la calidad de vida el trabajo-CVT y estimular el bienestar en el lugar de trabajo, las áreas de gestión de personas y salud ocupacional no siempre tienen éxito. Esta falla parece estar relacionada con el fenómeno de la resistencia de los usuarios a los nuevos programas o servicios ofrecidos en una institución. Como la promoción de QWL en el Servicio Público Federal es reciente, las acciones consistentes con una política de promoción y protección de la salud de los trabajadores significan una innovación en la institución investigada. Dado que tal promoción de CVT es un nuevo tipo de servicio que se ofrece, para llevarlo a cabo, es necesario romper las resistencias o barreras que surjan de las variables individuales o situacionales en la organización. Por lo tanto, resaltar las concepciones sobre CVT que surjen de la experiencia diaria de los servidores e identificar las resistencias percibidas por ellos en la adopción de estos programas, sirve como punto de partida para apoyar la formulación de estrategias que superen estas barreras. Se revelaron cuatro 
concepciones y cuatro resistencias que se recomiendan considerar para conseguir una implementación efectiva de las acciones de promoción de QWL.

Descriptores: Resistencia a la innovación; Concepciones vividas; Calidad de vida y Salud en el trabajo; Empleado estatal; Análisis interpretativa cualitativa.

\section{Introdução}

O mundo econômico e social, com sua economia competitiva e constante busca por qualidade dos bens e serviços, vem transformando as organizações e os processos produtivos, visando eficácia, eficiência com efetividade das organizações, em especial as organizações públicas criadas para atender a sociedade.

Entretanto, alerta Chanlat (1) as exigências por eficácia vão além do contexto financeiro, pois dizem respeito, também, às exigências sociais como: satisfação, saúde, estabilidade no emprego e segurança no trabalho, entre outras. Neste panorama de transformação presente no mundo organizacional do trabalho, o homem como o agente que realiza o trabalho é capaz de conferir-lhe qualidade distintiva nas organizações que buscam manter-se competitivas e inovadoras no setor de atuação.

$\mathrm{Na}$ relação de trabalho, neste estudo, são abordados mútuos interesses. De um lado os trabalhadores, sua vivência laboral e as suas percepções sobre a organização no panorama de inovações iniciadas para propiciar-lhes Qualidade de Vida no Trabalho- QVT e principalmente para a saúde laboral. De outro, as equipes responsáveis pela implantação destes programas que no início enfrentam resistências dos usuários.

Nesse contexto, mediante pesquisa aplicada, se revelaram as concepções dos servidores decorrentes de sua vivencia laboral e se identificaram as resistências desenvolvidas para adotarem programas de QVT. Para tanto, desvendou-se a seguinte questão de pesquisa: Quais são as concepções sobre QVT decorrentes da vivencia e as resistências para implantação dos programas de promoção de QVT?

A resposta alcançada confere relevância prática e teórica a esta pesquisa porque (i) fornece subsídios para elaborar programa de gestão em QVT pertinente à realidade organizacional examinada, pois inclui a perspectiva da experiência vivida dos servidores - usuários das ações de QVT, de uma universidade federal pública brasileira; (ii) evidencia empiricamente o conceito de concepções decorrentes da vivência como efetivas orientadoras de ações individuais no processo de aprender e desenvolver competências profissionais nas organizações apontado por Sandberg ${ }^{(2)}$.

\section{Referencial Teórico}


A QVT foi discutida por Walton ${ }^{(3),}$ quem a conceitua de forma abrangente como a incorporação das necessidades e aspirações humanas no ambiente laboral. Engloba condições físicas, psicológicas e sociais do ambiente de trabalho nas organizações.

Promover saúde e Qualidade de Vida no Trabalho ${ }^{(4)}$ significa, na atualidade, um desafio para as organizações, dado que ainda se trabalha num contexto dualista de separação do trabalhador do seu trabalho. Defende Limongi- França ${ }^{(5-6)}$ que a QVT é um conjunto das ações organizacionais que visam à implantação de melhorias e inovações gerenciais, tecnológicas e estruturais no ambiente de trabalho. Logo segundo a autora ${ }^{(5)}$ QVT significa: promover satisfação laboral do indivíduo na organização, estrutura de trabalho adequada e promoção à saúde do trabalhador.

Para minimizar impactos à saúde decorrentes da atividade laboral e assim o aparecimento de doenças ocupacionais prejudiciais do bem-estar dos trabalhadores e capazes de afetar o engajamento no trabalho, são necessárias medidas de promoção á saúde dos trabalhadores ${ }^{(7)}$. Adequar o trabalho ao ser humano ${ }^{(8)}$ é forma de se promover saúde aos trabalhadores. Pois um ambiente ergonomicamente adequado se destaca por diminuir a incidência das Lesões por Esforços Repetitivos e os Distúrbios Osteomusculares Relacionados ao Trabalho.
Deve-se reconhecer, também, no mesmo contexto da QVT, que os seres humanos compõem as organizações e cabe tratá-las não como extensões da máquina, mas propiciando, conforme aponta Lahy equilíbrio entre automatismo humano no trabalho moderno e ausência de constrangimento. Significa que priorizar alcance de execução técnica de atividades em detrimento da saúde do trabalhador pode tornar-se contraproducente à própria sobrevivência organizacional

Cabe às instituições públicas aferir a Qualidade de Vida no Trabalho como defendem Coelho, Harb e Sousa Veiga (4). Pois segundo os autores, ela é capaz de revelar se há satisfação ou insatisfação dos servidores em relação ao trabalho e, em aferindo-a, poder-se-ia subsidiar ações como a sua promoção mediante melhoria do ambiente laboral interno, ratificando-se o compromisso da organização com o bem-estar no trabalho e a melhoria continua.

Logo, o cuidado com a QVT surge em contextos de inovação organizacional e não perde relevância, mesmo sendo há muito estudada, devido às transformações do mundo do trabalho e dos trabalhadores nelas inseridos. Incluindo-se as inovações como as provocadas pela tecnologia e a automação no nível dos processos de trabalho na organização ${ }^{(10)}$. Nesse aspecto, parece que com a dinâmica econômica, cultural e de produção propiciadora da transformação do 
conhecimento e da tecnologia, os trabalhadores acabam expostos a um cenário laboral de inovação constante.

Inovação é definida, segundo o manual de Oslo da Organisation for Economic Co-Operationand Development$\mathrm{OECD}^{(11)}$ como: implantação de um produto (bem ou serviço) novo ou significativamente melhorado, ou de um processo, ou novo método organizacional para a prática de negócios na organização.

Inovação, para Damanpour ${ }^{(12)}$ significa elaboração e utilização de novas ideias ou condutas em uma organização. Uma nova ideia pode ser um novo produto, um novo serviço, um novo método de produção, um novo mercado, uma nova estrutura organizacional ou, um novo sistema administrativo, como por exemplo, uma inovação organizacional ou administrativa para implantar programas promoção de QVT de abordagem preventiva no lugar das vigentes abordagens corretivas ou assistencialistas.

Sendo assim, nesta pesquisa, entendese inovação como a utilização de uma tecnologia social de gestão que envolve metodologias organizacionais relacionadas à forma de gerir os vários processos dentro de uma instituição, de Gestão da saúde e Qualidade de Vida no Trabalho - GQVT. A GQVT nas organizações parece ter surgido com o intuito de suprir uma demanda social e de se ratificar um compromisso concreto com o seu trabalhador. Contudo, no setor público apenas recentemente em 2016, foi instituída a Política de Atenção à Saúde do Servidor Público Federal - PASSPF $^{(13)}$ para desenvolver novas estratégias de promoção e proteção à saúde dos trabalhadores visando a Gestão da saúde e QVT nas organizações públicas.

Nesse cenário, resistências emergem perante a inovação organizacional a qual se promove devido à maior demanda social, para acompanhar crescente competição, por determinação de novas leis ou regulamentos, ao adotar novas tecnologias (14). Para Hernandez e Caldas ${ }^{(14)}$ resistir a uma mudança refere-se ao fenômeno que ocorre pela percepção de se tratar de uma ameaça ao equilíbrio, ou seja, a resistência se apresenta a partir da realidade vivida por um indivíduo ou grupo.

A resistência à mudança segundo Hernandez e Caldas ${ }^{(14)}$ se fundamenta em duas variáveis, as individuais e as situacionais que influenciam o trabalhador tanto na sua percepção sobre mudança como na adoção de comportamentos frente a tal mudança. As "variáveis individuais", pelas quais a percepção pessoal sobre a realidade da mudança pode promover diferentes respostas, tais como: (i) Adoção espontânea a mudança; (ii) Decisão de superar a resistência; (iii) Conduta de comportamento resistente e (iv) Indecisão. Já as "variáveis situacionais" atuariam sobre o trabalhador, ou seja, são 
estímulos do ambiente organizacional, tais como: (i) cultura organizacional, (ii) crenças compartilhadas,

necessidades organizacionais, (iv) compromisso da alta gerência, (iv) conflitos internos, (vi) divisão de trabalho, (vii) inércia da organização e, (viii) solidariedade grupal.

Nesse sentido, os autores destacam que "as variáveis individuais e situacionais são tão importantes, ou mais, que o processo de percepção em si mesmo, uma vez que em condições de mudança organizacional essas variáveis moderam todos os estágios do processo de percepção da mudança, influenciando a maneira como cada indivíduo cria a sua própria percepção da realidade"(12).

Já em outra abordagem não dualista sobre a mudança organizacional e resistência a ela, Silva e Vergara ${ }^{(15)}$ se opõem a visão fragmentada da administração, não separando o individuo do ambiente organizacional. Para os autores (15) “a mudança deve ser tratada dentro de uma organização além do foco estratégico, do processo ou da tecnologia. A gestão da mudança deve reconhecer, à dimensão social, a possibilidade dos trabalhadores de não apenas adaptar-se a ela”.

Assim, para Silva e Vergara (15), na dimensão social, cabe aos indivíduos dentro de um contexto de mudança atuar como atores e sujeitos dentro no novo panorama organizacional. Para tanto, é fundamental que construa uma nova interação da organização com o trabalhador. Interação que não anule as emoções e percepções tais como ansiedade, medo e angústia. E estas emoções não devem ser interpretadas como simples resistências, apontam os autores, pois quando as organizações ignoram a leitura da percepção dos trabalhadores sobre a mudança, dificultam aceitação e o engajamento dos processos de mudança.

Para Durrive e Schwartz (16), os indivíduos engajam-se ao compreender uma mudança como uma melhoria ou a manutenção de um ambiente que julgam adequados. E podem rejeitar ou ignorar mudanças propostas na organização de acordo com os seus valores e necessidades.

Nesse sentido, assume-se neste estudo que adotar novas práticas de gestão significa uma inovação na organização ${ }^{(4-5-11)}$ e que, sendo entendidas e compartilhadas, as mudanças propostas podem ser incorporadas nas ações cotidianas e minimizariam as supostas resistências dos trabalhadores ${ }^{(2-15-16)}$ que vivenciam a mudança, neste caso, de práticas de gestão da saúde e QVT.

Reconhece-se com Sandberg ${ }^{(2)}$ que as vivencias laborais levam o indivíduo a assumir uma diferente concepção decorrente da vivencia própria, a qual, por sua vez, vai construindo mediante um ciclo de ação e vivencia, sua concepção própria sobre o cotidiano e essa que passa efetivamente a orientar suas ações. Quer dizer que os comportamentos apresentados no quotidiano da prática organizacional revelam vivências 
acerca de um fenômeno, das quais decorrem concepções orientadoras de novos comportamentos ou atitudes (16). Logo, as concepções $^{(2)}$ são os significados que os indivíduos desenvolvem a partir da vivência própria no quotidiano de trabalho, as quais passam efetivamente a orientar suas ações na organização, ou seja, as ações adotadas decorrem das concepções dos indivíduos.

Num contexto de ameaça ao equilíbrio, Rao ${ }^{(17)}$ apontou, a partir de estudo empírico, que o papel das práticas de gestão para mudança é o de mediar à dimensão cognitiva e a afetiva dos trabalhadores capazes de impactar no processo de mudança. $\mathrm{O}$ autor ${ }^{(17)}$ destaca que atitudes dos líderes durante o processo de mudança tais como uma boa comunicação sobre o processo, podem minimizar crenças negativas e assim favorecer atitudes positivas dos trabalhadores de adoção das práticas propostas durante a mudança.

Esta pesquisa aborda mudança organizacional decorrente das políticas de gestão que visam favorecer saúde e QVT, e, consequentemente, o bem-estar percebido pelos indivíduos no trabalho. E se preocupa também com o compromisso organizacional para superar as possíveis resistências que emergem num processo que busca promover saúde e QVT.

\section{Métodos}

Participantes

Foram realizadas entrevistas em profundidade mediante roteiro junto a dez servidores de uma universidade federal, localizada na Região Oeste da Baixada Fluminense do Estado do Rio de Janeiro, cujo quadro se compõe de aproximadamente 2700 servidores que atendem cerca de 20 mil alunos.

Sete dos entrevistados são servidores atuantes de um núcleo da Coordenadoria de Tecnologia da Informação- CTInf, setor com 14 servidores ao todo no qual se relata grande incidência de doenças ocupacionais como as Lesões por Esforço Repetitivo- LER, o que sugere existir condições laborais insuficientes e, assim, uma demanda para sua participação das ações de promoção de QVT. Além desse núcleo da CTinf., setor alvo desta pesquisa, também foram entrevistadas três servidoras dos setores que promovem e ofertam atividades destinadas a QVT, ou seja, a Coordenação de Saúde do Trabalhador- CST e o Sindicato dos Trabalhadores. O perfil desses servidores consta no quadro 01 .

Quadro 01: Perfil dos entrevistados por tempo de atuação no setor de trabalho

\begin{tabular}{|c|c|c|c|c|c|}
\hline Cargo & $\begin{array}{c}\text { Formação do } \\
\text { cargo }\end{array}$ & $\begin{array}{c}\text { Tempo na } \\
\text { instituição }\end{array}$ & $\begin{array}{c}\text { Tempo } \\
\text { no setor }\end{array}$ & Idade & Gênero \\
\hline
\end{tabular}




\begin{tabular}{|c|c|c|c|c|c|c|}
\hline \multicolumn{2}{|c|}{ Cargo } & $\begin{array}{c}\text { Formação do } \\
\text { cargo }\end{array}$ & $\begin{array}{c}\text { Tempo na } \\
\text { instituição }\end{array}$ & $\begin{array}{c}\text { Tempo } \\
\text { no setor }\end{array}$ & Idade & Gênero \\
\hline E1 & Coord. Substituta & Analista de TI & 44 anos & 44 anos & 66 anos & M \\
\hline E3 & Coord. Geral & Analista de TI & 09 anos & 09 anos & 36 anos & M \\
\hline E4 & Téc. Administrativo & Analista de TI & 08 anos & 06 anos & 31 anos & M \\
\hline E5 & Téc. Administrativo & Analista de TI & 05 anos & 05 anos & 29 anos & F \\
\hline E2 & Téc. Administrativo & Auxiliar Adm. & 06 anos & 03 anos & 44 anos & F \\
\hline E6 & Téc. Administrativo & Assistente Adm. & 01 ano & 01 ano & 29 anos & F \\
\hline E7 & Téc. Administrativo & Técnico em TI & 01 ano & 01 ano & 19 anos & M \\
\hline Coordenação de Saúde do trabalhador & Fisioterapeuta & 07 anos & 07 anos & 40 anos & F \\
\hline E9 & Téc. Administrativo & Psicóloga & 05 anos & 05 anos & 46 anos & F \\
\hline E8 & Coordenação & Assistente Social & 04 anos & 02 anos & 32 anos & F \\
\hline Sindicato dos Trabalhadores
\end{tabular}

Fonte: elaborada pelo autor com base no perfil dos entrevistados.

$\mathrm{Na}$ CTInf. da universidade pública federal pesquisada, o servidor com mais tempo trabalha há 44 anos na instituição e o de menos tempo, 01 ano. Destaca-se que 5 desses 7 entrevistados atuaram desde seu ingresso no mesmo setor. Na Coordenação de Saúde do trabalhador- CST a servidora com mais tempo de instituição tem 07 anos e a de menos tempo 05 anos na universidade $\mathrm{e}$ ambas atuam nessa seção desde seu ingresso na instituição. Já a servidora que atua como Coordenadora do Sindicato dos Trabalhadores está há 04 anos na instituição e há 02 na coordenação do sindicato. A idade dos sujeitos varia entre 66 e 32 anos. Quanto ao gênero, 4 servidores do gênero masculino e seis do gênero feminino.

Instrumentos
O roteiro das entrevistas foi elaborado sobre o conceito de QVT com base em Walton $^{(2)}$. Ferreira ${ }^{(7)}$ e Limongi- França ${ }^{(5)}$. E, para identificar as reações e comportamentos sobre QVT frente à mudança organizacional, usou-se a abordagem de Sandberg (2), Hernandez e Caldas ${ }^{(14)}$ e Silva e Vergara ${ }^{(15)}$

Procedimentos para coleta de dados e cuidados éticos

A coleta de dados foi feita no primeiro trimestre de 2017 mediante entrevistas semiestruturadas conduzidas com dois roteiros distintos. $\mathrm{O}$ primeiro roteiro levantou as percepções dos servidores sobre QVT. O segundo roteiro foi usado com a equipe que promove atividades destinadas à melhoria da saúde e QVT, ou seja, a CST e o Sindicato dos trabalhadores. Ambos constam no quadro 02. 


\section{Quadro 02: Roteiros de entrevistas utilizados}

\begin{tabular}{|l|l|}
\hline \multicolumn{2}{|c|}{ Primeiro roteiro de entrevista com servidores usuários do programa QVT } \\
\hline 1 & O que você entende sobre QVT? \\
\hline 2 & O que promove bem-estar e mal-estar no ambiente de trabalho? \\
\hline 3 & $\begin{array}{l}\text { Você tem conhecimento de algum setor da universidade que promove atividades destinadas a } \\
\text { melhoria da QVT? }\end{array}$ \\
\hline 4 & O que tem sido feito para melhorar a QVT no setor? \\
\hline 5 & Como você vê uma proposta ou programa de promoção à QVT? \\
\hline 6 & $\begin{array}{l}\text { No seu ponto de vista quais são as dificuldades ou resistências que as propostas ou programas } \\
\text { de QVT enfrentam na universidade? Por que você identifica estes pontos como resistências? }\end{array}$ \\
\hline \multicolumn{2}{|c|}{ Segundo Roteiro de entrevista com promotores de QVT: } \\
\hline 1 & Qual é o seu ponto de vista sobre QVT na universidade? \\
\hline 2 & $\begin{array}{l}\text { O seu setor desenvolve atividades de promoção ou programas de QVT? Se sim, quais } \\
\text { atividades? }\end{array}$ \\
\hline 3 & $\begin{array}{l}\text { Como você percebe a atitude dos servidores que participam das atividades de promoção ou } \\
\text { programas de QVT? }\end{array}$ \\
\hline 4 & $\begin{array}{l}\text { Na prática, quais são as resistências enfrentadas para realizar as atividades de promoção ou } \\
\text { programas de QVT propostos? Por que você identifica estes pontos como resistências? }\end{array}$ \\
\hline
\end{tabular}

Fonte: elaborada pelo autor.

Previamente as entrevistas, a pesquisa foi submetida e autorizada pelo Comitê de ética da universidade federal pesquisada. Em ambos os roteiros de entrevista levantou-se, na perspectiva dos entrevistados, resistências para adoção de programas da promoção de QVT.

$\mathrm{Na}$ realização da entrevista forneceram-se informações iniciais aos participantes com os objetivos da mesma; apresentou-se o Termo de Consentimento Livre e Esclarecido- TCLE bem se assegurou seu anonimato, a sua participação ser voluntaria e o seu direito de abandonar a pesquisa a qualquer momento, caso assim desejasse.

Procedimentos para a análise dos dados
Visando identificar as concepções sobre QVT e resistências percebidas pelos servidores entrevistados sobre sua resistência a adoção dos programas de QVT, os dados assim coletados foram transcritos na íntegra e o conteúdo dos textos foram interpretados qualitativamente nos termos de $\operatorname{Bardin}^{(18)}$. Gerando-se 07 categorias descritivas do fenômeno de resistência a adoção de práticas de saúde e QVT para responder a questão central desta pesquisa, na perspectiva dos entrevistados: Quais são as concepções sobre QVT decorrentes da vivência laboral dos servidores e as resistências desenvolvidas para adoção dos programas de promoção de saúde e QVT?

Em seguida, foram elaboradas deduções baseadas nessa análise interpretativa 
dos dados empíricos, este processo foi composto por: pré-análise dos textos das entrevistas, exploração do material, tratamento dos resultados e a interpretação dos mesmos.

\section{Resultados}

Nesta seção se apresentam os resultados da pesquisa de campo e à luz do referencial teórico, o resultado de campo respondendo a questão desta pesquisa na perspectiva empírica mediante uma matriz de categorias emergentes sobre o fenômeno de QVT vivido pelos entrevistados e sobre o fenômeno das resistências a adoção de programas de QVT ofertados na organização.

Assim, explicita-se $\left(1^{\circ}\right) \quad \mathrm{O}$ que significa QVT mediante 4 concepções desenvolvidas pelos trabalhadores na vivencia laboral e, $\left(2^{\circ}\right)$ Quais são as resistências percebidas à adoção de programas de QVT, na ótica do público alvo do programa de QVT e na ótica de quem promove as atividades de promoção em QVT.

Concepções dos Trabalhadores sobre QVT e Resistências percebidas ao Programa

Os trabalhadores em sua totalidade fazem referência ao ambiente laboral, em específico, (i) no que tange à relação entre as pessoas e as condições de trabalho, (ii) ao reconhecimento obtido e (iii) ao prazer que vivenciam no desenvolvimento de suas atividades laborais que os entrevistados reconhecem promover sua satisfação profissional.
Revelaram uma vivencia de bem-estar em seu ambiente laboral, de auto realização profissional, de trabalho em equipe e de boa relação interpessoal no setor. Um servidor expressa sentimento de bem-estar quando afirma na entrevista: "me identifico muito com meu trabalho... "Faço o que gosto e aqui todos nós somos colegas" (E1- Coordenador substituto da CTInf., 44 anos no cargo).

No que tange o mal-estar, seis dos sete entrevistados servidores da Coordenadoria de Tecnologia da Informação- CTInf apontam a estrutura física de trabalho deficiente, destacando a falta de espaço para comportar a equipe, mobiliário inadequado para executar a atividade, iluminação e climatização inadequadas. Os servidores relatam prejuízos à sua saúde causados por esta estrutura que passou a ser percebida deficiente, prejuízos como adoecimento por lesões osteomusculares e por estresse físico/psicológico. Assim ilustra o depoimento: "aqui se carece do mínimo de estrutura para executar o trabalho" (E4Analista de TI da CTInf., 6 anos no setor).

Três servidores dos sete entrevistados deste setor queixaram-se de pouco incentivo para o crescimento profissional no que se refere à capacitação. Quatro dos sete servidores da CTInf manifestaram a carência de pessoal para cumprir a demanda do setor provocando uma vivência de sobrecarga que tem gerado estresse no ambiente de trabalho. 
Os servidores afirmaram existir reconhecimento do trabalho no âmbito da equipe, mas o mesmo não acontece no contexto organizacional intersetores. Como ilustra a seguinte fala:

"nós aqui na Coordenadoria de Tecnologia da Informação não queremos ser reconhecidos como o coração da Universidade, mas a comunidade desta universidade deveria entender a importância do nosso trabalho. Pois, por exemplo, sem internet quase tudo aqui para (...)”. (E2coordenador de núcleo, 3 anos no setor).

Sobre o que tem sido feito para melhorar a saúde e QVT no setor, cinco dos servidores afirmaram existir um projeto em andamento para promover reforma física do local, e para dois servidores nada é feito. Seis dos sete servidores destacaram, que a chefia reconhece o esforço despendido individualmente e pela equipe para superar as dificuldades estruturais físicas e de pessoal. Assim, os servidores entrevistados da Coordenadoria de Tecnologia da Informação reconheceram que a chefia flexibiliza prazos e negocia com a administração superior visando melhorar as condições de trabalho.

Sobre a oferta de atividades para promover saúde e QVT, dos sete servidores alvo, cinco apontaram a Coordenação de
Saúde do Trabalhador - CST e o Sindicato dos Trabalhadores. Alguns servidores apontaram como promotores de QVT também a Pro-Reitoria administrativa da universidade, o Departamento de guarda e vigilância do campus, a Coordenação de desenvolvimento de pessoas e a Divisão de saúde da universidade. Mas, dois responderam que desconhecem setores que promovem esse tipo de atividade.

Os servidores que conhecem os respectivos programas relataram ter participado ou participarem de uma ou mais ações promovidas por estes setores e ainda reconheceram como de benefício para o contexto laboral, o fornecer cuidados preventivos para manter saúde ocupacional evitando os agravos a saúde quando se instala o adoecimento.

Um servidor relatou, também, já ter ficado afastado do trabalho para tratamento da própria saúde e atualmente participa de atividades de promoção desenvolvidas pela Coordenação de Saúde do trabalhador. Esta percepção positiva se evidencia no relato: "agora eu entendo como é importante eu manter uma boa postura quanto estou fazendo o meu trabalho sentado $e$ a importância das pausas, assim as minhas costas não doem no fim do dia."(E4- Analista de TI da CTInf, 6 anos no setor) Parece que as atividades que promovem QVT ainda carecem de suficiente divulgação, visto que no mesmo setor uns servidores 
desconhecem esse trabalho feito na concepções desenvolvidas pelos que instituição. No quadro 03 se sintetizam as vivenciaram a QVT nesse ambiente laboral.

Quadro 03: Concepções dos servidores da Coordenadoria de Tecnologia da InformaçãoCTInf sobre QVT e as percepções de bem-estar e mal-estar vivenciados no ambiente laboral.

\begin{tabular}{|c|c|c|c|c|}
\hline $\begin{array}{l}\text { Significado } \\
\text { atribuído } \\
\text { a saúde e QVT } \\
\text { vivenciadas }\end{array}$ & $\begin{array}{c}1^{\mathrm{a}} \text { concepção } \\
\text { Condições físicas } \\
\text { de trabalho }\end{array}$ & $\begin{array}{c}2^{a} \text { concepção } \\
\text { Satisfação com o } \\
\text { trabalho }\end{array}$ & $\begin{array}{c}3^{\mathrm{a}} \text { concepção } \\
\text { Reconhecimento das } \\
\text { realizações }\end{array}$ & $\begin{array}{l}4^{\mathrm{a}} \text { concepção } \\
\text { Relações } \\
\text { interpessoais }\end{array}$ \\
\hline $\begin{array}{l}\text { Positivo de } \\
\text { Bem-estar } \\
\text { vivenciado: }\end{array}$ & Não satisfatórias & lização & Chefia & Trabalho em equipe \\
\hline \multicolumn{5}{|c|}{ Ex: "me identifico muito com meu trabalho... faço o que gosto e aqui todos nós somos colegas" } \\
\hline $\begin{array}{l}\text { Negativo de } \\
\text { Mal-estar } \\
\text { vivenciado: }\end{array}$ & $\begin{array}{c}\text { Falta } \\
\text { infraestrutura e } \\
\text { adoecimento }\end{array}$ & $\begin{array}{c}\text { Sensação de } \\
\text { sobrecarga }\end{array}$ & $\begin{array}{c}\text { Falta de reconhecimento } \\
\text { da instituição e } \\
\text { comunidade }\end{array}$ & $\begin{array}{l}\text { Limitação das } \\
\text { atividades que } \\
\text { promovem QVT }\end{array}$ \\
\hline \multicolumn{5}{|c|}{$\begin{array}{l}\text { Ex: "aqui se carece do mínimo de estrutura para executar o trabalho" } \\
\text { "a demanda de trabalho... aqui agente não para (...)". } \\
\text { “(...) a comunidade desta universidade deveria entender a importância do nosso trabalho". } \\
\text { (...) são poucos os servidores na CST. }\end{array}$} \\
\hline
\end{tabular}

Fonte: Elaborada pelo autor com base na análise de conteúdo dos depoimentos.

Diante destas categorias descritivas, evidenciou-se quatro concepções dos trabalhadores decorrentes de suas vivencias sobre saúde e QVT: Condições físicas; satisfação com o trabalho; reconhecimento das realizações e Relações interpessoais pelas quais estes atribuíram significados positivos e negativos no ambiente de trabalho ${ }^{(3-5-6-8)}$. Positivos a QVT vista como: (i) satisfação e autorrealização), (ii) boas relações interpessoais com a chefia e colegas, (iii) compromisso individual e coletivo com o trabalho e, negativos tais como: (i) falta de estrutura para o desempenho das atividades, (ii) estresse e sobrecarga, (iii) falta de reconhecimento da organização, (iv) carência de atividades para promoção de saúde e QVT.

Sobre a percepção da importância de um programa de QVT, na sua totalidade responderam percebê-lo como uma oportunidade de benefício da própria saúde e melhoria na execução do seu trabalho. Logo, os servidores revelaram uma atitude positiva (16-17), uma resposta comportamental de aceitação conforme entendem o significado da promoção em saúde como um processo de mudança para melhoria. Começam a perceber diferença entre uma abordagem assistencialista quando já há o adoecimento, e uma abordagem preventiva de promoção de saúde e QVT por terem vivenciado seu benefício.

Assim, no ponto de vista dos servidores - alvo, embora reconheçam as ofertas preventivas de saúde nos programas 
de QVT na instituição e que sejam benéficos, os servidores promotores dos referidos programas defrontam-se com quatro tipos de resistências impedindo sua adoção e atingir sua meta ou seja, promover QVT e saúde laboral. São elas: (1) excesso de burocracia, tanto pelas dificuldades de participar das atividades de promoção frente as demandas de trabalho como para aquisição de materiais solicitados; (2) falta de pessoal para desenvolver o trabalho, percebem o efetivo de servidores destinados a promoção de saúde de QVT ser desproporcional ao efetivo total de trabalhadores, posto que são 12 servidores atuando na CST para atender um efetivo total de 2700 servidores; (3) falta de recursos financeiros da instituição para manutenção das instalações, equipamentos e atendimento das demandas para adequar e modernizar a estrutura física de trabalho e (4) falta de compromisso da alta gerência pois ainda não são previstos no plano de desenvolvimento institucional programas voltados a promoção de saúde e QVT, mas acreditam que tal inclusão formal como política institucional facilitaria obter dotações orçamentárias para este fim.

Explicitou-se, assim, que, para estes servidores responsáveis pela promoção de saúde e QVT, as resistências enfrentadas à adoção de um programa preventivo de saúde e QVT correspondem as variáveis situacionais, nos termos de Hernandez e Caldas ${ }^{(14)}$ como: inércia da organização, divisão de trabalho e compromisso da alta gerência.

Resistências vivenciadas e percebidas pelos Promotores das Atividades de QVT

Em busca da perspectiva dos servidores da Coordenação de Saúde do trabalhador - CST, foi seguido o segundo roteiro de entrevista com dois servidores, abordando os seguintes aspectos: concepção da QVT e resistências aos programas de QVT existentes. A CST na universidade pesquisada é uma coordenação que desenvolve três eixos de atividades: de perícia em saúde, de promoção em saúde e de saúde e segurança no trabalho. Busca através dos dados obtidos destes três eixos identificar as causas de adoecimento e agravos à saúde dos trabalhadores e com base nestes dados, desenvolver suas atividades de promoção a QVT.

Os entrevistados da CST manifestaram reconhecer a QVT importante para eles, porém ainda "precária" na Universidade. Precariedade esta evidenciada na estrutura física como nos "prédios envelhecidos e com pouca conservação, mobiliário desgastado e inadequado que dificulta realizar as atividades e promovendo adoecimento dos servidores" (E 9- Psicóloga, 5 anos no setor). Neste sentido, o fator estrutura física de trabalho é proposto por Walton ${ }^{(3)}$ como um dos critérios influenciadores da (in) satisfação no trabalho e quando percebido inadequado, 
segundo Ferreira ${ }^{(8)}$ promovem adoecimento e sensação de mal-estar laboral.

Ao responder afirmativamente que o setor de Coordenação de Saúde do trabalhador

- CST promove atividades destinadas para melhoria de QVT mencionou-se as atividades de: avaliação ergonômica, programa de preparação para aposentadoria, apoio psicológico, curso para gestores, vacinação ocupacional e outros. Mas, para os entrevistados o efetivo da equipe CST ainda é pequeno para atender os servidores da universidade, e o próprio setor carece de estrutura física mínima para desenvolver suas atividades. Assim, para eles um quadro de servidores e estrutura física insuficientes restringem a atuação do próprio setor e revelam viver QVT também precária.

Os dois servidores do setor responsável, CST apontaram ser fundamental desenvolver com mais frequência ações destinadas para saúde e QVT e destacaram a importância de promover parcerias com os outros setores da própria universidade para fomentar um programa forte de QVT assim como o de adequação da estrutura física da universidade.

No próprio setor CST se reconhece que este poderia ser um propulsor destas atividades, mas: "faltam pernas para sua equipe, pois aqui o quadro de servidores ainda é pequeno "Com apenas doze servidores para atender um efetivo de aproximadamente 2700 servidores da universidade" (E 8- Fisioterapeuta, 7 anos no setor).

Assim, consideram ter enfrentado esta dificuldade para promoção de saúde e QVT de forma ainda ampla, devido ao desproporcional efetivo de que dispõe.

Sobre a atitude dos servidores de diferentes setores da universidade que participam ou já participaram dos programas, no setor de Saúde do Trabalhador se considera como positiva porém ainda reativa, só quando a doença aparece. Como se ilustra no depoimento:

Há uma participação crescente [dos servidores nos programas de QVT que ofertamos], com boa interação e divulgação para colegas. Mas, ainda existe uma cultura ou uma ideia de [ser] atividade assistencialista por parte dos servidores que aderem os programas. Os servidores aderem às atividades na sua grande maioria, por exemplo, quando já apresentam algum problema, lesões por esforço repetitivo, stress, conflitos no ambiente de trabalho. Há uma carência por uma cultura de prevenção. (E9- Psicóloga, 05 anos no setor).

As resistências enfrentadas pelos ofertantes dos programas de saúde QVT de acordo com a vivência cotidiana dos dois 
servidores CST são, principalmente: de cunho cultural, pelo pessoal reduzido e pela estrutura física do próprio setor como limitantes das ações para toda a organização.

Assim, a resistência cultural se revelou ao se considerar QVT em seu caráter assistencialista ao invés de um caráter preventivo, significando para os entrevistados da CST uma resistência. Logo, foi explicitada uma percepção de necessitar-se construir uma nova cultura de prevenção da saúde, ou seja, estimular a inserção do servidor como ator e não apenas um indivíduo receptor das ações de promoção de saúde e QVT, como apontado por Silva e Vergara ${ }^{(15),}$ e para tal, atingir a dimensão social dos indivíduos no contexto de promoção da QVT. Promover uma visão assertiva e integrativa na dimensão social para efetivar uma cultura preventiva e não assistencialistas da QVT.

$$
\text { Evidenciou-se, assim, um }
$$
entendimento dos promotores de QVT da Coordenação de Saúde do Trabalhador de se tratar de resistências geradas relativas às variáveis situacionais discutidas por Hernandez e Caldas ${ }^{(14),}$ ou seja, limitações da própria instituição. Para atender as necessidades dos trabalhadores e a carência de práticas de gestão que favoreçam a promoção da QVT. Especificamente, compromisso da alta gerência e inércia da organização devido à percepção de carência de pessoal e estrutura adequada para esses servidores desempenharem o trabalho.
Sobre a concepção de QVT percebida no ponto de vista da Coordenação do Sindicato, esta é reconhecida como complexa. O próprio sindicato dos trabalhadores, da universidade pesquisada, desenvolve atividades para promover a QVT, principalmente, "na luta cotidiana contra o assédio, violência no trabalho, reivindicando um plano de carreira e melhor condição laborais. QVT é complexa, por falta de estrutura e por relações conflituosas no ambiente de trabalho" (E10- coordenadora do sindicato, 2 anos na função). Contudo, apontou pouca participação do servidor:

O sindicato considera a participação dos servidores nas atividades desenvolvidas por eles ainda pequena, provavelmente por um processo histórico $e$ político. No qual lutas no passado fizeram com que se desenvolvessem crenças, por parte dos trabalhadores. No qual houve suspeitas de interesses políticos dos sindicatos em conflito com o real interesse dos trabalhadores, nas lutas sindicais. (E10- coordenadora do sindicato, 2 anos na função)

Ficou exposto na vivência de E10 que as principais resistências na organização para a promoção de saúde e QVT estão na estrutura física, especificamente na falta condições de trabalho e em políticas que 
envolvem o trabalho da alta gestão. Esta carência sempre foi pauta das ações reivindicatórias sindicais, mas não se atendem, pois alega-se que dificuldade de mudar esta realidade, radica em questões financeiras da universidade. Segundo a entrevistada a questão das políticas institucionais e de recursos financeiros para a adequação da estrutura física de trabalho deve ser considerada: "como uma prioridade e que precisa avançar muito".

Logo, também, segundo os entrevistados da Coordenação de Saúde do Trabalhador e do sindicato, se evidenciaram as variáveis situacionais e a questão cultural de uma visão de saúde assistencialista como resistências vividas a adoção dos programas de QVT ofertados.

Nesse sentido, com base em Hernandez e Caldas ${ }^{(14)}$ e Silva e Vergara ${ }^{(15),}$ revelaram-se resistências para efetivar as novas práticas preventivas de promoção de saúde e QVT : (1) falta de envolvimento da alta gestão ou burocracia; (2) falta de pessoal; (3) falta de recursos financeiros ou falta de infraestrutura e (4) falta de uma cultura preventiva do adoecimento.

Quadro 04 -Fatores de não adoção e resistências aos programas de QVT

\begin{tabular}{|c|c|c|}
\hline Categorias & Trechos ilustrativos & Entrevista \\
\hline \multirow{2}{*}{$\begin{array}{l}\text { 1.Falta de envolvimento da alta } \\
\text { gestão/ } \\
\text { Burocracia }\end{array}$} & $\begin{array}{l}\text { "gostaria de participar das atividades de } \\
\text { prevenção, mas não tenho tempo (...)" }\end{array}$ & E5 \\
\hline & $\begin{array}{l}\text { "já foi solicitado material novo, mobiliário } \\
\text { ergonômico, mas falam que nunca vai chega" }\end{array}$ & E7 \\
\hline \multirow[t]{2}{*}{ 2.Falta de pessoal } & $\begin{array}{c}\text { "há poucos servidores atuando na saúde do } \\
\text { trabalhador (...)" }\end{array}$ & E8 \\
\hline & "faltam pernas para sua equipe (...)" & E1 \\
\hline \multirow{2}{*}{$\begin{array}{l}\text { 3.Falta de recursos } \\
\text { financeiros/Falta infraestrutura }\end{array}$} & $\begin{array}{c}\text { "Precariedade esta evidenciada na estrutura } \\
\text { física" "prédios envelhecidos e com pouca } \\
\text { conservação (...)" }\end{array}$ & E9 \\
\hline & $\begin{array}{c}\text { "como uma prioridade e que precisa avançar } \\
\text { muito". }\end{array}$ & E10 \\
\hline $\begin{array}{l}\text { 4.Falta de uma cultura } \\
\text { preventiva } \\
\text { adoecimento }\end{array}$ & $\begin{array}{l}\text { "Os servidores aderem às atividades na sua } \\
\text { grande maioria, por exemplo, quando já } \\
\text { apresentam algum problema (...)" }\end{array}$ & E8 \\
\hline
\end{tabular}

Fonte: Elaboração própria com base na análise de conteúdo as entrevistas.

\section{Considerações Finais}

Nesta pesquisa, identificou-se 04 resistências aos programas de QVT na ótica dos trabalhadores, seus representantes sindicais e na ótica dos responsáveis pela execução dos programas de promoção.

A necessidade de promover saúde e QVT é reconhecida pelos trabalhadores, mas 
para estes programas se tornarem efetivos cabe antes superar as resistências apontadas para sua execução e efetiva adoção. Evidenciou-se necessário superar as resistências presentes nas variáveis situacionais, ou seja, nos estímulos do ambiente organizacional, tais como: compromisso da alta gerência e inércia da organização a fim de superar questões burocráticas, da infraestrutura e de sobrecarga de trabalho por servidor. Outra resistência evidenciada está na cultura dos servidores, que reduz o significado da promoção de saúde e QVT estando ainda centrada no adoecimento em detrimento da prevenção como proposto pelas as atividades de promoção de saúde e QVT.

Portanto, superar tais resistências requer envolver o esforço de diferentes setores e dos próprios servidores para assumirem papel de sujeitos e não apenas receptores das ações de promoção de QVT, nesse cenário, cabe inovar pelo diálogo, como proposto por Silva e Vergara ${ }^{(15)}$. Um novo diálogo capaz de fortalecer a cultura de promoção à prevenção da saúde e uma cultura participativa pois sendo todos envolvidos perceberão o seu papel ativo de sujeito de sua própria saúde.

Como implicações práticas desta pesquisa, recomenda-se: (i) incluir a GQVT no Plano de Desenvolvimento Institucional PDI como uma macro estratégia organizacional abrangendo a instituição como um todo; (ii) estimular a internalizarão na organização como uma inovação na gestão de uma cultura de prevenção ao adoecimento e QVT no lugar de apenas reação a doença instalada. Para tanto, incluir as concepções e perspectiva dos envolvidos; (iii) efetivar tal inovação estimulando mudança das concepções decorrentes da vivencia laboral dos servidores e assim propiciar as mudanças com base na vivência positiva de QVT.

Destarte, melhorias na QVT podem refletir positivamente não somente na saúde e no bem-estar dos trabalhadores, mas na atitude de atuar positivamente na Qualidade do Serviço Prestado- QSP.

No que se refere às limitações da presente pesquisa aplicada, reconhece-se que sendo um estudo de caso, carece estender a pesquisa a outros setores da organização e programas de QVT em outras universidades federais para alcançar uma generalização analítica dos resultados deste estudo.

A pesquisa traduz concepções de servidores decorrentes da própria vivência em uma única universidade pública, localizada na baixada fluminense do Rio de Janeiro. Logo os resultados aqui apontados podem não abranger uma vivência compartilhada por servidores em outras instituições publicas.

Outra limitação tange a própria transformação acelerada presente no contexto laboral de inovação e automação contemporâneo para produção de bens e serviços. Logo novas demandas e novos contextos que surgirem no mundo econômico social e de produção de bens e serviços mudarão as vivencias suas concepções e 
percepções sobre o fenômeno de saúde e QVT.

Assim, sugere-se aprofundar estudos que levem sempre em consideração as próprias vivencias do quotidiano laboral dos servidores no contexto atual, tanto político, organizacional, social, econômico e o de inovação.

\section{Referências}

1. Chanlat, J.-F. (2000). Ciências Sociais e Management. São Paulo: Atlas.

2. Sandberg, J. (2000). Understanding human competence at work: an interpretative approach. Academy of Management Journal, 43(1), 9-25. Recuperado de https://psycnet.apa.org/record/200100562-001.

3. Walton, R. E. (1973). Quality of working life: what is it? Sloan. Management Review, 15(1), 11- 21.

4. Coelho, M. I. B. A., Harb, A. G., \& Veiga, R. S. S. (2017). Qualidade de vida no trabalho em uma instituição pública da cidade de Manaus. Revista Gestão \& Saúde (Brasília), 08(02), 212 -229. Recuperado de https://www.researchgate.net/profile/Mois es_Coelho2/publication/317409435

5. Limongi-França, A. C. (2004). Qualidade de vida no trabalho- QVT: conceitos e práticas nas empresas da sociedade, pósindustrial. São Paulo: Atlas.

6. Oliveira, R. R., Silva, I. B., Castro, D. S. P., \& Limongi França, A. C. (2013). Qualidade de vida no trabalho - QVT dos professores de ensino técnico federal: os fatores biopsicossociais e organizacionais de satisfação. Revista de Administração da UNIMEP, 11(2),143-173. Recuperado de

https://www.redalyc.org/pdf/2737/273728 673007.pdf.
7. Almeida, C. G. S. T., \& Fernandes, R. C. P. (2017). Distúrbios musculoesqueléticos em extremidades superiores distais entre homens e mulheres: resultados de estudo na indústria. Revista Brasileira de Saúde Ocupacional, 42(3), 1-10. Recuperado de https://www.redalyc.org/pdf/1005/100550 852002.pdf

8. Ferreira, M. C. (2011). Qualidade de vida no trabalho: uma abordagem centrada no olhar dos trabalhadores. Brasília, DF.

9. Lahy, J. M. (2017). O sistema Taylor e a fisiologia do trabalho profissional. Laboreal, 13(2), 65-66. Recuperado de http://www.scielo.mec.pt/scielo.php?pid= $\underline{\mathrm{S} 1646-}$ $\underline{52372017000200007 \& \text { script }=\text { sci_arttext }}$ $\underline{\text { \&thg=es }}$

10. Silva, D., \& Vasconcelos, R. (2017). Entre a (pre) determinação e as possibilidades de regulação: uma proposta metodológica para interpretar a adoção e uso de tecnologias enquanto escolhas organizacionais. Laboreal, 13(2), 9-23. Recuperado de http://www.scielo.mec.pt/scielo.php?scrip $\underline{\mathrm{t}=\text { sci_arttext\&pid=S1646- }}$ $\underline{52372017000200002}$

11. Organisation for Economic Co-Operation and Development. (2005). Manual de Oslo: diretrizes para coleta e interpretação de dados sobre inovação. Eurostat. Recuperado de https://www.finep.gov.br/images/apoio-efinanciamento/manualoslo.

12. Damanpour, F., \& Wischnevsky, J. D. (2006). Pesquisa sobre inovação nas organizações: distinção inovação geradora de organizações que adotam a inovação. Journal of Engineering and Technology Management, 4(23), 269-291.

13. Pacheco, M. V. (2015). Uma análise da implementação da Política de Atenção à Saúde do Servidor Público Federal com foco na equipe multiprofissional (Dissertação de 
Mestrado). Faculdade de Medicina, Universidade Federal Fluminense, Niterói, RJ, Brasil.

14. Hernandez, J. M. D. C., \& Caldas, M. P. (2001). Resistência à mudança: uma revisão crítica. Revista de Administração de Empresas, 41 (2), 31-45. Recuperado de

http://www.scielo.br/pdf/rae/v41n2/v41n2 $\underline{\mathrm{a} 04}$

15. Silva, J. R. G., \& Vergara, S. C. (2003). Sentimentos, subjetividade e supostas resistências à mudança organizacional. Revista de Administração de Empresas, 43(3), 10-21. Recuperado de http://www.scielo.br/pdf/rae/v43n3/v43n3 a02.pdf

16. Durrive, L., \& Schwartz, Y. (2008). Glossário da Ergologia. Laboreal, 4(1), 23-28. Recuperado de: http://laboreal.up.pt/revista/artigo.php?id $=48 \mathrm{u} 56 \mathrm{oTV} 6582234396587$

17. Rao, M. S. (2015). The tools and techniques of effective change management: Why some reformers succeed while others fail. Human Resource Management International Digest, 23(1), 35-37.

18. Bardin, L. (2011). Análise de conteúdo. São Paulo: Edições 70

\section{Participação dos autores:}

Palma AV trabalhou na concepção teórica, coleta de dados, análise qualitativa, elaboração e redação final do texto;

Villardi QB trabalhou na concepção teórica, análise qualitativa, elaboração e redação final do texto;

Recebido: 26.07.2019

Revisado: 12.08 .2019

Aprovado: 13.09.2019 